\title{
INSTITUTIONALIZING OF PROPERTY RELATIONS IN THE SYSTEM OF NETWORK COORDINATION NEXUS
}

\author{
Sergey D. Mokichev ${ }^{1}$ \\ Lilia F. Zulfakarova ${ }^{2}$ \\ Tina M. Vakhitova ${ }^{3}$
}

\begin{abstract}
There is an active development and use of the principles and research tools of the institutional approach in modern economic science. It allows establishing the relationships that exist between the economic, political and social elements of the system, expanding the boundaries of economic life. The institutional environment determines the goals, functions and dynamics of interaction in property relations. Thus, it appears the effectiveness of functioning of its various forms, which will depend on the institutional structure of management as a system of norms and rules that determine the configuration of property rights, together with coercive instruments. The article considers the approach from the theory of constructivism, which describes the
\end{abstract}

structural features of property relations, taking as a basis the system of network coordination of relations. Formation of a network structure and a new, nonhierarchical way of coordinating ties reflects new economic realities associated with the strong interdependence of property subjects. Formation of a knowledge economy, development of globalization, integration of property subjects have led to the accelerated development of innovations, to a new quality of property relations. Innovations are supported by a huge agglomeration of social, innovative, intellectual and financial capital, which forms the emergence of "innovations in innovations" and determines the relevance of studying the

1 Kazan federal university, Russia, Kazan. Email: mokichev.kpfu@mail.ru, $+79196985967$

2 Kazan federal university, Russia, Kazan. Email: mokichev.kpfu@mail.ru, $+79196985967$

3 Kazan federal university, Russia, Kazan. Email: mokichev.kpfu@mail.ru, $+79196985967$ 
system of network coordination of relations.

Keywords: property, property relations, institutional structure, network structure, triple helix, property relations, innovation system

\section{Introduction}

The main feature of the network system is the network logic of using the property, which gives the appropriation relations special qualities and functions. This means that the situation of continuous updates of property relations is associated with a certain institutional environment, where horizontal-network communications predominate between property subjects. It is in such an environment that the constructivism of property relations, designed to generate innovations, is most clearly manifested. The dynamics of "innovations in innovations" is the driving force for the formation of constructivism of property relations in the system of network coordination of relations. The theory of constructivism of property relations allows not only checking the mechanisms of relations between property subjects for strength, but also adjusting them to develop such a partnership that would lead to a hybrid socio-economic structure that has the advantages of linking the spiral structures of property subjects and increased adaptability to changes in the external environment. There is a transformation in the behavior of all economic agents. The use of the triple helix model is focused on institutional processes leading to the definition of new "rules of the game" in the network space, identifies the main generating source of economic and social development, which in turn makes it possible to take to a new level the interaction of participants in the innovation process. In the 2000 s, the partnership construction of property subjects began to be introduced into economic practice as the basis for the formation of network structures and the generation of innovations [3], as a model for organizing new property relations. It also quite often began to appear in the scientific conferences as a new approach to the processes of integration of various property subjects and the creation of a single knowledge market.

We reflected the constructivism of property relations in the analysis of the triple helix, in the analysis of regional 
institutional formations and in substantiating the theory of the evolution of property relations in the coordination system of ties [1] [7], which made it possible to propose a new mechanism for constructing property relations capable of ensuring self-development of complex network systems. Configured for a dynamic innovation environment, the constructivism of property relations harmonizes at all levels of economic interaction of property subjects.

The development of the theory of constructivism of property relations is explained by the transition of economic systems to a network structure. This civilizational shift is caused by a weighty dynamism of the environment, an increased level of interdependence of property subjects and a constantly high level of uncertainty. Continuous changes, often perceived as the "tyranny of the moment", led to the transition of property relations to a new, super-plastic construction and to a new way of coordinating relations between subjects. An innovative economy forces property owners to be flexible, adapt to a changing world, and act adequately in order to survive.

\section{Methods}

To enhance innovation, such a structure of property relations is necessary that is highly adaptable to establishing coordination relations with all participants in the innovation sphere. In this regard, the transition of economic systems to a network structure is necessary, in which coordination of relations will be most effective. Today it is already obvious that it is impossible to predict and construct property relations exclusively from the position of rational knowledge of the industrial system. Here we need non-rational cognitive mechanisms that allow expanding the criteria for the scientific nature of property relations and going beyond their canonical interpretation.

The network way of coordinating relations between the property subjects changes the usual structure of assignment relations to a network one, being much more plastic than the hierarchy model.

The practice of market contracts of property owners goes online, based not on price signals, but on direct cooperation between owners, producers and consumers. Large owners, creating a new economic environment, develop 
coordinating platforms, on which the economic networks grow [10]. The level of innovation activity of the property subjects is changing, the coordination of relations between owners in the fields of science, education, production, as well as at the levels of the system of scientific personnel reproduction, the organizational support of the chain "applied research - experimental development - production" are being increased. Property relations evade any hierarchical closed-loop structures and vertical subordination. They line up on horizontal ties and collaboration principle. Collaboration is understood as such a mechanism of interaction between owners, when the cooperation subjects constantly exchange knowledge, mutually using their potential, and coordinate their decisions. In the literature, this mechanism is called "coordination of communication without hierarchy" [6], or "colloborative governance" [2].

The process of involving owners in the network is accompanied by the pooling of resources, ideas, coordination of action plans to create an innovative product. Property relations become a smooth system-forming element of the network economy system. Active interaction of the property subjects lies in their activities to ensure the most complete, comprehensive and effective use of the capabilities of the network economy in their interests. This approach is updated within the framework of the evolutionary theory of the activity of property relations and leads to the creation of the advantages of network interaction of property subjects: high degree of adaptation to changing environmental conditions; absence of territorial restrictions, focus of property subjects on the development of their core competencies and elimination of duplication of functions; attraction of competent partners with the necessary resource potential to the network; possibility of forming an association of entities for the implementation of complex projects with many participants; high level of innovative activity.

Since the network economy is based on the principle of collaboration and innovation, which change the activity of property subjects, they are characterized by a conscious interest of owners in cooperative ties; in the selection of property subjects according 
to established criteria; in the formalization of competencies; in assessing the resource potential; in ensuring the convergence of competencies and complementarity of resources based on highlighting the strengths and weaknesses of property subjects in the network economy; in the design of integration education, taking into account the common goals and strategic directions of development; in determining indicators for assessing the effectiveness of owner interaction; in the formation of internal and external culture of owner interaction within the framework of a network based on the collaboration principles.

On the basis of coordination of relations in the network interaction of property subjects, a new model of the structure of property relations arises, transforming traditional ideas about the nature of appropriation relations. Network coordination of relations between property subjects is a fairly stable design based on a balance of interests of its participants, a system of internal norms and rules, a unified network culture of property relations. Showing a certain kind of interest and initiative in innovative activity, the property subject develops directions for coordinating relations closely related to innovations that can generate new knowledge, technologies, and production methods. The owners form a toolkit for coordinating relationships to create a single interaction environment.

Coordination of relations between the property subjects can have almost any area of activity of the owners as its object:

- $\quad$ scientific and technical activities;

- innovation activity;

- formation and development of relationships, knowledge, abilities associated with the development and production of hightech products with unique consumer properties;

- effective use of intellectual potential;

- intellectual property management system.

Constructivism of property relations in the process of forming the coordination relations between subjects is based on two initial criteria: 1) the main forms that coordination agreements can take; 2) various owners involved in coordination. 
Four coordination forms of information exchange between owners can be distinguished:

1. creation of joint $\mathrm{R} \& \mathrm{D}$ units;

2. specialization;

3. license sharing;

4. creation of a joint venture. When analyzing the various owners involved in the coordination, those types of competencies of the owner that can benefit the network organization are identified If such actions are aimed at compensating for the owner's weaknesses, then they can be called compensators, if to strengthen competencies - amplifiers. As coordination relationships develop, competencies are ranked by their ability to maximize compensating or amplifying effects.

It is much more difficult to identify the owner's potential with a double effect. Opportunities of the owner in a network organization, which compensate for shortcomings and at the same time strengthen its advantages, are of fundamental importance for a successful innovation process. ,

Communication coordination between property partners in a network structure dramatically reduces the cost of analyzing random opportunities. The developed coordination links in the networks contain a quantitative assessment of how these potential opportunities for creating an innovative product correspond to them. They are ranked according to the degree of possibility, which allows determining the risk and make an assessment. As David Thiis notes [11], an understanding of the potential of relationships and a focus on value creation lead to radical changes in property relations.

\section{Results And Discussion}

One of the main benefits of coordinating network relationships between owners is to prevent catastrophic decisions made in the hustle and bustle of using random methods to evaluate the potential capabilities of appropriation entities. The solution to the problem is the "wheel of opportunity" a method of creating a strategy for the production of an innovative product in stages. This method is formed in the process of searching for answers to the following fundamental questions: 
- What are the strengths and weaknesses of ownership entities included in the network structure to create an innovative product?

- What alternative opportunities for partnership of property owners do we have?

- What are the owners' priorities for increasing strengths and eliminating weaknesses?

- How do the potential capabilities of the property subjects meet the criteria of network organization in an innovative economy?

The process of building the "wheel of opportunities" begins after a decision is made on the horizontal coordination of connections in the network education; change in the institutional activity of legislators, holders of rights and carriers of duties [9]; reducing uncertainty and responding to complex situations through risk sharing [5]; redistribution of property rights [4].

Reduction of the period between invention and implementation requires a new structure of property relations and new incentives. The partner owners are developing a coordinated plan for the development of the innovation process, which provides for the transfer of potential opportunities to the "wheel of opportunities". Then, criteria are developed for selecting future alternatives based on an analysis of the strengths and weaknesses of the property subjects to match their innovative economy. After comparing alternative options for concentrating ownership on the "wheel of opportunities" using the innovation criterion, priority areas of innovation are identified. This is a very sensitive area of property relations sometimes partners in coordinating relations in the network structure spend years developing their competencies for an innovative economy and can react negatively, if the opportunities they offer are unceremoniously rejected without proper analysis of the suitability of the innovative economy. The business relationship of the partner owners can be defined as an ongoing process, within which strong social, economic, and technical ties are formed to reduce costs and increase value, thereby achieving mutual benefits [3]. As noted by A. Mitchell [8]: "In real life, the exchange between people is much richer than a market deal. There is an exchange and 
sharing not only material, but also moral values in the communication process...”.

\section{Summary}

Constructivism of property relations in the network education gives rise to a coherent, interconnected and mutually agreed world. The constructing owner and the appropriation relationships constructed by it constitute procedural unity. Construction means that the owner assumes the entire burden of responsibility for the implementation of property relations in the field of innovative production. The responsibility principle is at the forefront. The owner constructs an appropriation relationship from the perspective of an innovative economy and synergistic effect. Constructivism determines the owner's role, attitudes of his/her consciousness and his/her value preferences in the choice of possible ways of developing an innovative economy in a state of instability of the national innovation system. The owner constantly discovers completely new situations that could not even have imagined previously. Entering the network allows the owner understanding how one can achieve a certain goal and

\section{7}

choose certain means of achieving it using horizontal coordination of connections. At the same time, he/she simultaneously refuses the opportunity to implement other goals that he/she values less, but believes that he/she could achieve them with less risk to his/her property. The value that the owner refuses is its costs, which are a purely subjective assessment.

\section{Conclusions}

The backbone nature of property relations determines the significance of their changes in the innovative development of the economic system as a whole. The qualitative transformation of property relations as a system-forming element has activated political, sociocultural, spiritual, moral and other institutions that shape the external environment of the economic system, violating intrasystemic ties and civilizational integrity. As a rule, in network education, the owners act, because they subjectively assess the value of innovative goals higher than the costs they plan to incur, hoping to get a higher income from the property. 


\section{Acknowledgements}

The work is performed according to the Russian Government Program of Competitive Growth of Kazan Federal University.

\section{Bibliography}

Mokichev S.V., Mokichev S.D. Razvitie innovatzionnoj kooperatziy kak uslovie transformatziy struktury sobstvennosti [Development of cooperation as a condition for transformation of ownership structure] / Jurnal Economichescoj Teoriy. 2012. №3. p.27-38.

Andersson T, Schwaag-Serger S, Sörvik J, Wise E. Cluster Policies Whitebook. IKED - International Organization for Knowledge Economy and Enterprise Development, 2004. P. 266.

Anderson, J \& Narus J (1998) Business Marketing: Understand What Customers Value / Harvard Business Review, Nov/Dec98, Vol. 76 Issue 6, p53-65.

Demsetz H. Toward a Theory of Property Rights / The American Economic Review, Vol. 57, No.2, Papers and Proceedings of the Seventy-ninth Annual Meeting of the American Economic Association. (May, 1967), pp. 347-359.

Gibbons R., Farrell J. Cheap Talk about Specific Investments / The Journal of Law, Economics, and Organization, Volume 11, Issue 2, October 1995, Pages 313-334.

Hasumi Y. Roles of International Organizations and the EU in Governing the Global Economy: Implications for Regional Cooperation in Asia / The Third EU-NESCA Workshop, Korea University, May 2007.

Mokichev S.D., Mokichev, S.V., Gerasimova V. Nano-economics In a National System of Innovation / Procedia Economics and Finance, 2013. p. 288-297.

Mitchell A. It's Now a Matter of Trust / Marketing Business, No33, April, 2001.

Riker W. H., Itai Sened. A Political Theory of the Origin of Property Rights / American Journal of Political Science, Vol. 35, No. 4, 1991. p.951-969 
Tapscott D., Anthony D. Williams,

Wikinomics: How Mass Collaboration

Changes Everything / New York:

Penguin, 2007, 320 pp.

Teece David J. Managing Intellectual

Capital: Organizational, Strategic, and

Policy Dimensions / Oxford University

Press, 2002. ISBN-13: 9780198295426 